\title{
Mobilizing the CSWB measurement community: Reflections from the Interactive National Dialogue on Research, Evaluation, and Analysis of Hub/Situation Tables in Canada (January 24-25, 2017: Toronto)
}

\author{
Chad R. Nilson*
}

In January of 2017, evaluators $(\mathrm{n}=15)$, analysts $(\mathrm{n}=14)$, and supporters $(\mathrm{n}=34)$ of the "Hub Model of Collaborative Risk-Driven Intervention" gathered in Toronto to spearhead a national dialogue on measurement. For the first time in Canada, key stakeholders involved in Hub/Situation Tables mobilized to explore opportunities to share, collaborate, and build capacity for future development of knowledge, evidence, and practice. In co-hosting this event, Cal Corley (Community Safety Knowledge Alliance), Laura Huey (University of Western Ontario), and I (University of Saskatchewan), believed that by bringing the measurement and practitioner/ policy communities together for shared dialogue, we would better understand the challenges, opportunities, and next steps toward not only building scientific rigour around the Hub Model, but facilitating shared ownership and motivation for ongoing measurement and analysis.

Since the launch of Canada's Hub Model in 2011, a growing body of literature has continued to inform us of the achieved target group, process, progress, and early outcomes of Hub/Situation Tables. In particular, analyses of table data (Campbell, 2016; Global Network for Community Safety, 2016; Gray, 2016; Lamontagne, 2015; Nilson, 2016a; North Bay Parry Sound District Health Unit, 2015; Winterberger, 2015) inform us of risk factors, agency involvement, and intervention outcomes. Evaluations of Hub/Situation Tables report on service access for clients (Babayan, Landry-Thompson \& Stevens, 2015; Ng \& Nerad, 2015; Nilson, 2014), benefits to agencies (Nilson, 2016b; Nilson 2017a), client satisfaction (Brown \& Newberry, 2015; Nilson, 2017a); improved clientservice provider relationships (Nilson, 2016c; Nilson, 2017a), improved agency-to-agency communication ( $\mathrm{Ng} \&$ Nerad, 2015), improved community relationships (Brown \& Newberry, 2015; Litchmore, 2014), table performance (Clement, 2016), risk reduction (Brown \& Newberry, 2016), and client outcomes (CMPA, 2016; Newberry \& Brown, 2017). Other research contributions on the Hub Model explore cost-savings analysis (Sawatsky, Ruddell \& Jones, 2017), key indicators in community safety and well-being (Nilson, 2015), suggestions for future methodology (Nilson, 2016d), and opportunities for offering remote presence applications of collaborative risk-driven intervention through communication technology (Nilson, 2017b).

During the past six years, many of the researchers, evaluators, and analysts responsible for this growing body of knowledge connected with one another informally. However, periodic phone calls or e-mails could never replace the value of face-to-face dialogue. Therefore, in bringing everyone together, we wanted to maximize our collective potential for exploring how we can strengthen measurement of the Hub Model. In doing so, a series of topics were selected-each with a representative of the measurement community facilitating the dialogue.

In opening the event, Cal Corley (Community Safety Knowledge Alliance) invited us to use this event as the starting point for ongoing dialogue on improved measurement for community safety and well-being. Following this, I provided an overview of the current state of evaluation/ analysis across Canada. Next, Laura Huey (University of Western Ontario) discussed the importance of strengthened methods and deliverables. Taking us into the evening, Norm Taylor (Journal of Community Safety and Well-Being) delivered a keynote address on the role of fidelity, data access, and evidence in the future of community safety and well-being.

On the second day, Claudia Tenuta and Emily Jefferson (Ontario Ministry of Community Safety and Correctional Services) provided an overview of Ontario's experience with the Hub/Situation Table Database (Nilson, Winterberger \& Young, 2015). Following this, Markus Winterberger (Community Mobilization Prince Albert) facilitated dialogue on opportunities to improve the database. Later in the morning, 
Jason Newberry and Jamie Brown (Taylor-Newberry Consulting) led a group discussion on overcoming challenges in measurement of the Hub Model. After lunch, I facilitated a discussion on performance indicators in community safety and well-being. Ending the event, Cal Corley highlighted the linkage between evidence and practice. ${ }^{1}$

Throughout the event, dialogue among participants revealed a few shared experiences from across the country. The first was that in the past five years, the evaluation process has helped to inform and strengthen application of the Hub Model. Furthermore, there continues to be a growing appetite for formative evaluation at newer tables and summative evaluation at more experienced tables. Another common experience is that, in addition to collecting data, the Hub/Situation Table Database has been one of the most effective tools for protecting privacy, while also keeping the Hub/Situation Table discussion process disciplined and structured. A third commonly shared experience is that, once communities are able to engage in evaluation and analysis, they quickly realize the untapped potential for creating better understanding of how to meet their community's needs.

Another major focus of the event was to identify some of the common challenges in measurement, and share strategies for overcoming these obstacles. During this discussion, we learned that evaluators are often challenged by the fact that a Hub/Situation Table is not a single entity, but rather a consortium of multiple agencies with different evaluation interests, analytical priorities, information-sharing thresholds, and data collection capacity. Also, agency leaders often expect immediate measures on long-term outcomes that are difficult to attribute directly to the Hub/Situation Table. From a technical perspective, the de-identified nature of the Hub/Situation Table Database limits opportunity to link table data to outcome data from agencies. Furthermore, there is a definite trade-off between improving data collection for evaluative/analytical purposes and improving data collection for operational purposes. Finally, despite the value and interest in evaluation and analysis, not all communities have the financial means or internal capacity to engage in these measurement activities.

Some of the solutions posed to these and other challenges discussed include: role clarification in the measurement process, set reasonable expectations for communities, and gather client consent for data linkage. Concerning the pressure to measure long-term impacts, several event participants agreed that we must reiterate that the Hub Model does not extend beyond basic triage. Therefore, casting longer-term evaluation methodologies may potentially be premature.

Another key discussion at the event was performance indicators in community safety and well-being. Throughout the event, close to 40 indicators were identified by participants. These can be grouped into five categories: collaboration, service mobilization, risk reduction, community safety and well-being (sector specific), and community safety and well-being (aggregate). In wrapping up the discussion, four main suggestions were offered for developing strong performance indicators: 1) take a systemic approach to indicator development; 2) measure what you are intending

For a more thorough overview of the event, please see the event proceedings posted at www.cskacanada.ca/ projects. to measure; 3) do not let one indicator define the entire Hub Model-instead, involve multiple indicators; 4) explore protected data collection from lead agencies immediately before/ after a Hub/Situation Table discussion.

As both a facilitator and coordinator of this event, I was very inspired by the energetic dialogue, sound logic, and unwavering passion that many participants had for proper measurement of the Hub Model. In reflecting on the entirety of the event, I felt that there were three shared realizations that emerged. The first is that on a national scale, we need a fidelity tool that solicits conformity to the model. Without that, it becomes very difficult to measure collaborative riskdriven intervention across time and space. The second is that there must be consistency in the variables used in the Hub/ Situation Table Database. Having comparability of Hub/Situation Tables between and within various regions is important for reliable measurement. The third is that, as a field, we have seen many developmental and formative evaluations of the Hub Model. However, we need to move to a place of summative evaluation that tracks, monitors, and reports on outcomes. Achieving the first two of these three realizations will certainly help with this.

In preparing the Summary of Proceedings document for this event (CSKA, 2017), I took the liberty of making 15 recommendations to the measurement and practitioner/ policy communities. These recommendations were based upon my own reflections on the event, as well as upon notes taken from a third-party dialogue recorder. In closing this narrative, I would like to highlight at least 5 of those recommendations:

1. Hub/Situation Table stakeholders should develop a national fidelity tool that will assist communities in complying with the core concepts and components of the model. Such consistency will create better opportunities for local, regional, provincial, and national measurement. It will also serve to clarify and reduce the risk of deviation from the established discipline and practices of the Hub Model.

2. In forming a Hub/Situation Table, partner agencies should include shared data collection, evaluation, and analysis as priority activities for signatories of their MOU.

3. The original authors of the Hub/Situation Table Database should work with a cross-section of stakeholders from across Canada to refine and improve the database for the whole country. Part of this effort would include a revised and re-distributed set of Database Guides and Description of Variables.

4. Communities (and their measurement assets) may want to consider using the Hub/Situation Table Database to begin capturing data on systemic issues. This will arm communities with important information required for the next stages of community safety and well-being: planning, alignment, barrier reduction, system improvement, etc.

5. Construct a sharing network within the measurement community that brings together researchers, evaluators, and analysts to continue collaborating and improving measurement of the model. 


\section{ACKNOWLEDGMENTS}

Many thanks to our event sponsors: Saskatchewan Ministry of Justice, Global Network for Community Safety, and Ontario Ministry of Community Safety and Correctional Services. Also, a big thanks and congratulations to the event coordinators: University of Saskatchewan, University of Western Ontario, Canadian Society of Evidence-Based Policing, and Community Safety Knowledge Alliance.

CONFLICT OF INTEREST DISCLOSURES

The author shares a business relationship with the Editor-in-Chief of this Journal.

\section{AUTHOR AFFILIATIONS}

${ }^{*}$ Centre for Forensic Behavioural Science and Justice Studies, University of Saskatchewan, Saskatoon, SK, Canada.

\section{REFERENCES}

Babayan, A., Landry-Thompson, T., and Stevens, A. (2015). Evaluation of the Brant Community Response Team Initiative: Six-month report. Brantford ON: Brant County Health Unit

Brown, J. and Newberry, J. (2015). An evaluation of the Connectivity Situation Tables in Waterloo Region. Addressing risk through system collaboration. Evaluation report submitted to Waterloo Region Connectivity Partnership. Guelph, ON: Taylor Newberry Consulting.

Campbell, E. (2016). Durham Connect: Situation table data analysis/analytical dashboard, 2016. Whitby, ON: Durham Regional Police Service.

Clement, L. (2016). Multiagency Early Risk Intervention Tables (MERIT): Pilot project review. Ottawa, ON: The Lansdowne Consulting Group.

CMPA. (2016). Hub: before \& after. In COR opportunities: A periodic series of observation papers for consideration by local and provincial decision makers, v.1, i.7, (September 30). Prince Albert, SK: Community Mobilization Prince Albert.

CSKA. (2017). Measuring collaborative risk-driven intervention: An interactive national dialogue on research, evaluation and analysis of the Hub/ Situation Table and related CSWB models (Summary of Dialogue: January 24-25, 2017 at Toronto, ON). Saskatoon, SK: Community Safety Knowledge Alliance.

Global Network for Community Safety. (2016). 1st Canada-wide accoun of Hub/Situation Table adopter sites and situations triaged for acutely elevated risk - Since 2011. Toronto, ON: Global Network for Community Safety. Retrieved from: http://globalcommunitysafety.com/sites/default/ files/Hub-Situation-Table-Adoption-1.pdf

Gray, S. (2016). Lanark County situation table project: Annual report, September 2015 - September 2016. Perth, ON: Lanark County Situation Table.

Lamontagne, E. (2015). Rapid Mobilization Table data analysis. Update: February, 2015. Sudbury, ON: Community Mobilization Sudbury.

Litchmore, R. (2014). Preliminary report on the progress of the Guelph Situation Table. Internal report provided to Guelph Situation Table. Guelph, ON: University of Guelph.
Ng, S., and Nerad, S. (2015). Evaluation of the FOCUS Rexdale Pilot Project. Delivered to the City of Toronto and Toronto Police Service. Toronto, ON: Vision and Results Inc. and SN Management.

Newberry, J., and Brown, J. (2017). An evaluation of the Connectivity Situation Tables in Waterloo Region: Phase II. Evaluation report submitted to Waterloo Region Connectivity Partnership. Guelph, ON: Taylor Newberry Consulting.

Nilson, C. (2014). Risk-driven collaborative intervention: a preliminary impact assessment of community mobilization Prince Albert's Hub Model. Saskatoon, SK: Centre for Forensic Behavioural Science and Justice Studies-University of Saskatchewan.

Nilson, C. (2015). Measuring change: A framework to support evaluation of collaborative risk-driven community safety and well-being in Ontario. Delivered to the Ontario Working Group on Collaborative Risk-Driven Community Safety. Prince Albert, SK: Living Skies Centre for Social Inquiry.

Nilson, C. (2016a). Year one analysis: a descriptive review of data captured through Collaborate Barrie's Collaborative Risk-Driven Intervention Initiative. Toronto, ON: Global Network for Community Safety.

Nilson, C. (2016b). Chatham-Kent's Fast Intervention Risk Specific Teams: Final evaluation report. Toronto, ON: Global Network for Community Safety.

Nilson, C. (2016c). Collaborative risk-driven intervention: A study of Samson Cree Nation's application of the Hub Model. Ottawa, ON: Public Safety Canada.

Nilson, C. (2016d). Canada's Hub Model: calling for perceptions and feedback from those clients at the focus of collaborative risk-driven intervention. Journal of Community Safety and Well-Being, 1: 58-60.

Nilson, C. (2017a). Collaborative risk-driven intervention evaluation brief: a preliminary analysis of discussion subject, table discussant, and key stakeholder satisfaction, understanding, and perceived impact of Collaborate Barrie. Toronto, ON: Global Network for Community Safety.

Nilson, C. (2017b). Collaborative risk-driven intervention: technology-enabled opportunities in rural and remote communities-a pilot project plan Saskatoon, SK: Centre for Forensic Behavioural Science and Justice Studies-University of Saskatchewan / Community Safety Knowledge Alliance.

Nilson, C., Winterberger, M., and Young, T. (2015). Hub Database description of variables: an overview of variables to be used in the Hub Database for purposes of tracking general information, risk factors and actions of hub discussions and collaborative interventions in Saskatchewan. Prince Albert, SK: Community Mobilization Prince Albert/Centre for Forensic Behavioural Science and Justice Studies-University of Saskatchewan.

North Bay Parry Sound District Health Unit. (2015). North Bay Gateway Hub: Data analysis 1-year report. North Bay, ON: North Bay Parry Sound District Health Unit.

Sawatsky, M., Ruddell, R., and Jones, N. (2017). A quantitative study of Prince Albert's crime/risk reduction approach to community safety. Journal of Community Safety \& Well-Being, 1:3-12

Winterberger, M. (2014). Report on the Hub discussions 2013/2014: A documentation of the Prince Albert Hub discussion study period: September 1, 2013 to August 31, 2014. Prince Albert, SK: Community Mobilization Prince Albert. 